\title{
ESTUDO EXPLORATÓRIO SOBRE OS ESTILOS INTELECTUAIS NO ENSINO MÉDIO
}

\author{
KATYA LUCIANE DE OLIVEIRA ${ }^{1}$ \\ AMANDA LAYS MONTEIRO INÁCIO² \\ ACÁCIA APARECIDA ANGELI DOS SANTOS 3 \\ MARIA LUZIA SILVA MARIANO ${ }^{4}$ \\ SANDRA APARECIDA PIRES FRANCO 5
}

\begin{abstract}
RESUMO: O objetivo do presente estudo foi descrever o perfil dos estilos de pensamento/intelectuais de alunos do ensino médio brasileiro. Também visou buscar possíveis diferenças entre os alunos do 1 을 ano do ensino médio e do 3 으o ano. Participaram 524 alunos do ensino médio de três escolas públicas, sendo uma do Estado do Paraná e duas de Minas Gerais. O instrumento de pesquisa foi o Inventário de Estilos de Pensamento/Intelectuais (TSI-R2), que apresenta sessenta e cinco itens, sendo aplicado de forma coletiva. Com base nos resultados foi possível verificar um perfil de estilos intelectuais dos alunos do ensino médio brasileiro, havendo diferença estatisticamente significante entre os grupos nos estilos local (preferência por ideias concretas e com muitos detalhes), hierárquico (preferência pela priorização de tarefas segundo sua importância) e anárquico (preferência por tarefas flexíveis).
\end{abstract}

Palavras-Chave: Estilos de aprendizagem. Avaliação psicológica. Educação básica.

\section{EXPLORATORY STUDY ON INTELLECTUAL STYLES IN HIGH SCHOOL}

ABSTRACT: The objective of the present study was to describe the profile of the thought / intellectual styles of Brazilian high school students. It also sought to find possible differences between students in the first year of high school and the third year. 524 high school students participated in three public schools, one in the state of Paraná and two in Minas Gerais. The research instrument was the Inventory of Thinking Styles / Intellectuals (TSI-R2), which presents sixty-five items, being applied collectively. Based on the results, it was possible to verify a profile of the intellectual styles of Brazilian high school students, with a statistically significant difference between the groups in the local styles (preference for concrete ideas and with many details), hierarchical (preference for prioritizing tasks according to their importance) and anarchic (preference for flexible tasks).

Keywords: Learning styles. Psychological evaluation. Basic education.

1 Professora do Departamento de Psicologia e Psicanálise (PPSIC), Programa de Mestrado em Psicologia e Programa de Mestrado e Doutorado em Educação da Universidade Estadual de Londrina - UEL.

2 Mestranda bolsista CNPq em Educação pelo Programa de Mestrado e Doutorado em Educação UEL.

3 Professora da Universidade São Francisco na graduação e Programa de Pós-Graduação Stricto Sensu em Psicologia. Membro titular do Comitê de Assessoramento na área da Psicologia do CNPq (2014-2017).

4 Doutoranda em Educação pelo Programa de Mestrado e Doutorado em Educação da UEL.

5 Professora do Departamento de Educação e do Programa de Pós-Graduação em Educação da Universidade Estadual de Londrina - UEL. 


\section{ESTUDIO EXPLORATORIO SOBRE LOS ESTILOS INTELECTUALES EN LA ENSEÑANZA MEDIA}

RESUMEN: El objetivo del presente estudio fue describir el perfil de los estilos de pensamiento / intelectuales de alumnos de la enseñanza media brasileña. También pretendió buscar posibles diferencias entre los alumnos de primer año y del 3 o año. Participaron 524 alumnos de la enseñanza media de tres escuelas públicas, una del estado de Paraná y dos de Minas Gerais. El instrumento de investigación fue el Inventario de Estilos de Pensamiento / Intelectuales (TSI-R2), que presenta sesenta y cinco ítems y fue aplicado de forma colectiva. Con base en los resultados fue posible verificar un perfil de estilos intelectuales de los alumnos de la enseñanza media brasileña, con diferencia estadísticamente significante entre los grupos en los estilos locales (preferencia por ideas concretas y con muchos detalles), jerárquico (preferencia por la priorización de tareas según su importancia) y anárquico (preferencia por tareas flexibles).

Palabras clave: Estilos de aprendizaje. Evaluación psicológica. Educación básica.

\section{Introdução}

A aprendizagem é um processo contínuo que ocorre durante toda a vida do indivíduo, podendo ser compreendida enquanto um fenômeno multifacetado e complexo que envolve múltiplas variáveis para que se efetive. Dentre essas variáveis estão o ambiente, as emoções, os valores, a cognição e a motivação do sujeito (OLIVEIRA; SANTOS; SCACCHETTI, 2016). Tendo como referencial teórico a Psicologia Cognitiva, embasada na teoria do processamento da informação, pode-se dizer que o conceito de aprendizagem abarca o monitoramento e a regulação do comportamento do aprendiz (WOOLFOLK, 2000).

A teoria do processamento da informação estuda os processos de aprendizagem, memória, percepção e o modo como as informações são processadas pelos indivíduos (STERNBERG, 2010). Analogicamente, para essa teoria, o funcionamento cognitivo pode ser comparado ao funcionamento de um computador, podendo adquirir, avaliar, arquivar e resgatar as informações conforme necessário. Diante dessa ideia, é possível dizer que o sujeito tem capacidade de decodificar e compreender uma nova informação, podendo recuperá-la e utilizá-la em um momento futuro. Além disso, possibilita compreender que o estudante, ao processar uma nova informação, torna-se interlocutor de seu próprio processo de aprendizagem (HANNON; DANEMAN, 2001).

Almeida (2002) evidencia a importância do papel ativo do sujeito na construção do seu conhecimento no momento da aprendizagem. Entre as habilidades ou competências necessárias ao aprendizado, o autor salienta a importância de que ele seja capaz de pensar e de aprender, visto serem habilidades fundamentais para o sucesso escolar. A respeito, Zhang e Sternberg (2005) destacam que 
o papel da escola na atualidade se tornou mais amplo e profundo, ao englobar outros aspectos relevantes, como a formação crítica e reflexiva do aluno, de forma a torná-lo mais compromissado com a sua própria educação.

Diversas abordagens teóricas vêm defendendo a concepção de que a educação formal deve ser orientada para a promoção do estudante responsável por seus próprios processos de aprendizagem (WOOLFOLK, 2000). Nessa direção, Boruchovitch (2007) salienta a necessidade de se transcender o ensino dos fatos e de se assegurar que ocorra a apropriação dos processos psicológicos pelos quais os alunos aprendem.

Dentre as etapas do ensino básico obrigatório brasileiro está o ensino médio, caracterizado pela necessidade de uma aprendizagem que ultrapasse os conteúdos formais, colaborando para uma formação ética, profissional e reflexiva dos estudantes que o frequentam, contribuindo na ampliação do círculo social desses jovens e ampliando suas experiências de vida a fim de auxiliar no desenvolvimento e construção de cada um enquanto sujeito (ABRAMOVAY; CASTRO, 2003). O ensino médio tem como particularidade, ainda, as questões de identidade e instabilidade dos estudantes, bem como aspectos que permeiam a constituição dos seus objetivos educacionais e curriculares que geraram importantes consequências nessa fase do ensino básico (FRIGOTTO; FRANCO; RAMOS; 2005).

Segundo Krawczyk (2014), observa-se uma expansão do ensino médio a partir da dácada de 1990, embora o compasso das pesquisas desenvolvidas neste contexto está muito aquém daquelas desenvolvidas em outras etapas da educação formal. Para a autora, uma das razões para tal fato seria a presença tardia de um projeto de democratização da educação pública brasileira que ainda nos dias atuais são se encontra finalizado, ocorrendo diversas mudanças ao longo dos anos que geram consequências para a educação pública de modo geral.

O ensino médio público brasileiro vem apresentando novos desafios causados por sua própria expansão, bem como pelas importantes mudanças no âmbito educacional, político e cultural que o país vive (KRAWCZYK, 2014). Diante desse quadro, evidencia-se a necessidade de estudos que englobem os alunos pertencentes ao ensino médio, possibilitando um olhar específico para os processos de ensino e aprendizagem inerentes a este período do ensino básico.

Considerando que os processos de aprendizagem ocorrem de maneira distinta em cada sujeito, dependendo de suas habilidades cognitivas e das particularidades de cada um, é importante considerar que cada sujeito apresenta uma forma preferencial utilizada para processar informações e 
lidar com as tarefas no momento do aprendizado. Essa maneira preferencial é denominada de estilo de pensamento ou intelectual, tratando-se de um campo pouco explorado na literatura científica brasileira (OLIVEIRA; SANTOS; SCACCHETTI, 2016; ZHANG, 2015; ZHANG; STERNBERG, 2005). O termo estilo intelectual foi utilizado pela primeira vez por Zhang e Sternberg no ano de 2005. Por ser considerado mais completo teoricamente, pode-se dizer que o termo engloba as demais construções de estilo empregadas anteriormente na literatura científica (FAN; ZHANG, 2014; ZHANG, 2015).

Durante as duas últimas décadas, o campo dos estilos vem se ampliando consideravelmente. Com o objetivo de organizar os modelos existentes na literatura sobre os estilos intelectuais, Zhang (2011) optou pela sistematização de seis modelos integrativos de estilos. Esses modelos são o proposto por Curry (1983) - modelo de cebola dos estilos de aprendizagem, Miller (1987) - modelo dos processos e estilos cognitivos, Riding e Cheema (1991) - modelo integrador de estilos cognitivos, Grigorenko e Sternberg (1995) - estilos sob enfoque da cognição, personalidade e atividade, Zhang e Sternberg (2005) - Theory of Mental Self-Government (Teoria do Autogoverno Mental) e Sadler-Smith (2009) - modelo duplo de estilo cognitivo. A seguir, serão expostas as principais características de cada um dos modelos a fim de uma melhor compreensão do campo de estilos.

O modelo proposto por Curry (1983) indica que os estilos apresentam diferentes graus de mobilidade. São organizadas as nove principais construções de estilo a um modelo semelhante às camadas de uma cebola, sendo a camada mais interna relacionada à personalidade, podendo ser considerada a menos suscetível a modificações. A camada média referente aos estilos que avaliam o processamento da informação e a camada externa se relaciona com medidas que avaliam a preferência do sujeito, sendo a mais suscetível à modificação. Tal modelo foi pioneiro dos estudos sobre a cognição, no entanto, não tem sido sistematicamente utilizado em pesquisas mais atuais sobre o tema (ZHANG, 2011).

O modelo de Miller (1987) é considerado como o dos processos e estilos cognitivos. Nele, os estilos abrangem diferenças individuais do modelo de processamento da informação, sendo composto por três processos cognitivos básicos, quais sejam, percepção, memória e pensamento. $O$ autor buscou relacionar seu modelo com outras áreas, no entanto, seu modelo não se relaciona com estilos que incluam atividades de aprendizagem (ZHANG, 2011; ZHANG; STERNBERG, 2005).

Riding e Cheema (1991) apresentaram um modelo baseado nas descrições, correlações, métodos de avaliação e efeito de mais de 30 estilos que poderiam ser agrupados em duas dimensões 
principais: holístico-analítico e verbal-hipotético. A primeira dimensão diz respeito ao fato de o indivíduo processar informações em sua totalidade ou em partes e a segunda se refere às representações das informações se darem por meio de pensamentos verbais ou imagens mentais. Apesar da busca dos autores em correlacionarem suas pesquisas com outras áreas como a neurociência cognitiva e as estratégias de aprendizagem, o foco do modelo seria a cognição humana (ZHANG, 2011).

O modelo de Gringorenko e Sternberg (1995) se mostra mais integrativo em relação aos demais citados anteriormente. Eles analisam os estilos sob três perspectivas principais: focada na cognição, considerando os estilos enquanto habilidades, focada na personalidade, sendo os estilos compreendidos com aproximação aos traços da personalidade e focada na atividade, sendo os estilos concebidos como mediadores de aprendizagem, envolvendo métodos de ensino (ZHANG, 2011).

O modelo proposto por Zhang e Sternberg (2005), em Theory of Mental Self-Government (Teoria do Autogoverno Mental), considera os estilos intelectuais tanto em relação à característica do processamento cognitivo quanto à preferência por determinadas tarefas. Ao contrário dos demais modelos apresentados, nesse modelo os estilos podem ser considerados mais ou menos adaptativos, dependendo das exigências estilísticas e de situações específicas. Além disso, os autores trazem pela primeira vez o termo estilos intelectuais para a literatura científica, construindo uma linguagem comum no contexto acadêmico (FAN, 2016; ZHANG, 2011; ZHANG; STERNBERG, 2005).

O modelo de Sadler-Smith (2009) propõe dois modos básicos de processamento da informação que podem ser empregados no processo de tomada de decisão, quais sejam, os estilos intuitivo e analítico. Enquanto o estilo intuitivo é considerado cognitivamente pouco exigente, mais afetivo, imagético, rápido na operação e de formação lenta, o estilo analítico, pode ser considerado como o oposto, cognitivamente exigente, conscientemente disponível, não é afetivo, simbólico, lento em operação, mas de formação rápida (ZHANG, 2011).

Cada um dos seis modelos de estilos integrativos propostos possuem características singulares e, de modo geral, buscam relacioná-los com outras áreas do conhecimento. No entanto, o modelo apresentado por Zhang e Sternberg (2005), denominado como Teoria do Autogoverno Mental, pode ser considerado o mais completo pela possibilidade de uso em contextos acadêmicos e não acadêmicos (FAN, 2016).

O modelo dos estilos intelectuais organizado a partir da Teoria do Autogoverno Mental faz 
uma aproximação entre as formas de governo da sociedade e as formas como os indivíduos escolhem governar suas próprias atividades, ou seja, tal analogia serviria para retratar como a mente funciona (ZHANG; STERNBERG, 2005). Nessa perspectiva, existem 13 tipos de estilos que são agrupados em cinco dimensões, sendo elas: função (legislativo, executivo e judicial), forma (monárquico, hierárquico, anárquico e oligárquico), nível (global e local), espaço (interno e externo) e tendência (liberal e conservadora) (EMIR, 2013; OLIVEIRA; INÁCIO; BURIOLLA, 2016; ZHANG; STERNBERG; FAN, 2013).

A organização dos estilos intelectuais pode ser feita ainda de acordo com a classificação: Tipo I, II e III. O Tipo I se relaciona a valores mais adaptativos, por se relacionar com traços da personalidade mais favoráveis. Assim, exige níveis mais altos de complexidade cognitiva e se relaciona com aspectos característicos da criatividade, compreendendo os estilos legislativo (envolve criatividade e escolha das próprias tarefas), judicial (preferência por avaliar o desempenho dos demais), hierárquico (prioriza tarefas segundo sua importância), liberal (tarefas sem procedimento fixo) e global (ideias abstratas) (ZHANG, 2015).

O Tipo II compreende um menor nível de complexidade mental, demonstrando uma tendência do sujeito ao cumprimento de regras na escolha e execução de suas atividades. Os estilos nesse tipo são: executivo (cumprimento de regras e atividades previamente definidas), monárquico (realização de uma tarefa por vez), local (ideias concretas e muitos detalhes) e conservador (regras e procedimentos fixos na realização da tarefa). Por fim, o Tipo III diz respeito a características que podem pertencer aos Tipos I e II, dependendo da demanda exigida pela tarefa a ser executada. Os estilos envolvidos nesse tipo são: oligárquico (múltiplas tarefas sem estabelecer prioridades), anárquico (preferência tarefas flexíveis), interno (realizar atividades individualmente) e externo (preferência por trabalhos em grupo) (FAN, 2016; ZHANG, 2011).

Apesar das especificidades de cada um dos estilos intelectuais, deve-se considerar que eles podem ser modificados e desenvolvidos, estando tal fato relacionado à necessidade e ao contexto do sujeito. Do mesmo modo, alguns estilos podem ser utilizados com a finalidade de aprimorar a aprendizagem do aluno, o que pode levar à melhoria do rendimento escolar relacionada ao uso de estilos combinados entre professor e aluno no momento da aprendizagem (GOMES; MARQUES; GOLINO, 2014; ZHANG, 2015). Nessa perspectiva, considera-se relevante o estudo dos estilos de aprendizagem em alunos do ensino médio, pois conhecer o perfil individual dos alunos permite ajustar as práticas pedagógicas ao modelo que melhor representa a cada um, ampliando as chances de que o aprendizado seja mais efetivo. No ensino médio, esse fato toma maior dimensão, porque esses alunos 
ingressarão no ensino superior e/ou no mercado de trabalho, por isto melhorar a qualidade da formação nesta etapa da educação formal é imprescindível.

Ao se considerar os estudos presentes na literatura científica acerca dos estilos intelectuais no ensino médio, que utilizam o Inventário de Estilos de Pensamento/Intelectuais (TSI-R2), evidenciase uma escassez de produções, principalmente em âmbito nacional, destacando-se neste contexto os estudos de Gomes, Marques e Golinho (2014) que investigaram a validade incremental dos estilos legislativo, executivo e judiciário no que tange ao rendimento escolar de alunos do ensino médio, tendo como controle a variável inteligência. Internacionalmente, é possível verificar o estudo de Tai (2012), que buscou analisar o impacto dos estilos de ensinar dos professores e dos estilos intelectuais dos alunos no momento da escolha profissional e ainda o de Zhang e Fu (2017), que buscou relacionar os estilos intelectuais e o estresse acadêmico em estudantes chineses.

O estudo de Zhang e Fu (2017) evidenciou que os estilos do tipo I se relacionam a estratégias de enfrentamento autodirigidas, ou seja, os alunos com preferência na utilização de estilos do tipo I são mais criativos, estando assim propensos a desenvolver melhores estratégias para solucionar seus problemas. No entanto, observou-se nos estudantes com preferência por estilos do tipo II correlação positiva ao abandono das estratégias de enfrentamento. Tal resultado faz sentido à medida que indivíduos no tipo II preferem seguir regras e demonstram baixo nível de complexidade cognitiva na realização das tarefas, assim, seguir as regras já existentes ao invés de sugerir novas soluções pode reduzir o estresse acadêmico.

Posto isso, o presente estudo pretendeu descrever o perfil dos estilos de pensamento/intelectuais de alunos do ensino médio brasileiro. Também visou buscar possíveis diferenças entre os alunos do 1 을 ano do ensino médio (ingressantes dessa etapa da escolarização) e do 3 ㅇ ano (concluintes).

\section{Método}

\section{Participantes}

Participaram 524 alunos matriculados no ensino médio de três escolas públicas estaduais, duas do Estado de Minas Gerais e uma do Paraná, sendo 71\% ( $n=372)$ participantes de Minas Gerais e $29 \%$ ( $n=152)$ do Paraná. O sexo feminino representou $57,8 \%$ ( $n=303$ ) e o masculino $42,2 \%(n=221)$. A idade média dos alunos foi de 16 anos e 5 meses $(D P=1,49)$, a idade mínima foi 14 anos e a máxima 
27. Dos participantes 242 eram alunos $(46,2 \%)$ do 1 o ano e $282(53,8 \%)$ do 30 ano do ensino médio.

\section{Instrumento}

Utilizou-se o Inventário de Estilos de Pensamento/Intelectuais - Thinking Styles Inventory TSI-R2 (STERNBERG; WAGNER; ZHANG, 2007). O TSI-R2 é de origem estadunidense e apresenta estudos que evidenciam sua validade para aquele contexto, com coeficientes de alpha de Cronbach variando de 0,70 a 0,80 .

O instrumento foi elaborado por Sternberg e Wagner (1992), em sua versão original apresentava 104 itens dispostos em uma estrutura teórica que se organizava em 13 estilos: legislativo, executivo, julgamento, global, local, liberal, conservador, hierárquico, monárquico, oligárquico, anárquico, interno e externo. Após foi realizada uma revisão do TSI, por Sternberg, Wagner e Zhang (2003), passando a apresentar 65 itens divididos novamente entre 13 estilos da teoria do Autogoverno Mental de Sternberg. As alternativas de resposta estão em em escala likert de sete pontos: "De jeito nenhum" (1 ponto), “Não muito bem" (2 pontos), "Um pouco" (3 pontos), "Bem de alguma forma" (4 pontos), "Bem" (5 pontos), "Muito bem" (6 pontos) e "Extremamente bem" (7 pontos) (Zhang, 2011). Novamente foi feita uma revisão do instrumento, proposta por Sternberg, Wagner, e Zhang (2007), totalizando também 65 itens e 13 dimensões. O Inventário de Estilos de Pensamento recebeu a denominação Revisado II (TSI-R2) (ZHANG, 2011). Cabe esclarecer que foi essa versão empregada no presente estudo. Cada dimensão abarca cinco itens, conforme pode ser visto na Tabela 1 
Tabela 1 - Dimensões e seus respectivos itens

\begin{tabular}{|c|c|c|}
\hline Dimensão & Itens & Exemplo \\
\hline Legislativo & $5,10,14,32$ e 49 & $\begin{array}{l}\text { Quando encontro um problema, eu uso minhas } \\
\text { próprias ideias e estratégias para resolvê-lo. }\end{array}$ \\
\hline Executivo & $8,11,12,31$ e 39 & $\begin{array}{l}\text { Eu gosto de descobrir como resolver um } \\
\text { problema seguindo certas regras. }\end{array}$ \\
\hline Judicial & $20,23,42,51$ e 57 & $\begin{array}{l}\text { Eu gosto de situações em que eu possa comparar } \\
\text { e avaliar formas diferentes de fazer as coisas. }\end{array}$ \\
\hline Global & $7,18,38,48$ e 61 & Eu tendo a prestar pouca atenção nos detalhes. \\
\hline Local & $1,6,24,44$ e 62 & $\begin{array}{l}\text { Eu prefiro lidar com problemas que exijam que } \\
\text { eu preste atenção a muitos detalhes }\end{array}$ \\
\hline Liberal & $45,53,58,64$ e 65 & $\begin{array}{l}\text { Quando eu enfrento um problema, eu prefiro } \\
\text { tentar novas estratégias ou métodos para } \\
\text { resolvê-lo. }\end{array}$ \\
\hline Conservador & $13,22,26,28$ e 36 & $\begin{array}{l}\text { Prefiro seguir regras ou maneiras prontas de } \\
\text { fazer as coisas. }\end{array}$ \\
\hline Hierárquico & $4,19,33,25$ e 56 & $\begin{array}{l}\text { Eu gosto de listar as coisas mais importantes que } \\
\text { preciso fazer antes de começar a fazê-las }\end{array}$ \\
\hline Monárquico & $2,43,50,54$ e 60 & $\begin{array}{l}\text { Quando escrevo ou converso sobre ideias, } \\
\text { prefiro focar em uma ideia de cada vez. }\end{array}$ \\
\hline Oligárquico & $27,29,30,52$ e 59 & $\begin{array}{l}\text { Ao discutir ou escrever sobre um tema, eu fico } \\
\text { com os pontos de vista aceitos por meus colegas. }\end{array}$ \\
\hline Anárquico & $16,21,35,40$ e 47 & $\begin{array}{l}\text { Eu posso facilmente mudar de uma tarefa para } \\
\text { outra, porque todas elas parecem-me ser } \\
\text { igualmente importantes. }\end{array}$ \\
\hline Interno & $9,15,37,55$ e 63 & $\begin{array}{l}\text { Eu gosto de controlar todas as fases de uma } \\
\text { tarefa sem ter que consultar outras pessoas. }\end{array}$ \\
\hline Externo & $3,17,34,41$ e 46 & $\begin{array}{l}\text { Quando começo uma tarefa, eu gosto de discutir } \\
\text { junto com meus amigos e colegas. }\end{array}$ \\
\hline
\end{tabular}

Fonte: Elaborado pelas autoras 
Foi realizada uma análise fatorial exploratória na qual a escala composta por 65 itens ficou organizada com o número total de 27 itens. Dessa forma, as dimensões ficaram assim distribuídas: Dimensão 1 - estilos executivo e conservador, com 8 itens $(\alpha=0,815)$, sendo 4 do executivo $(11,39,08$, 31) e 4 do conservador $(13,28,36,26)$; Dimensão 2 - estilos legislativo e interno, com 4 itens $(\alpha=0,705)$, sendo 2 do legislativo $(32,05)$ e 2 do interno $(63,55)$; Dimensão 3 - estilo externo, com 4 itens $(\alpha=0,798),(46,41,34,17)$; Dimensão 4 - estilo monárquico, com 3 itens $(\alpha=0,730),(43,54,60)$; Dimensão 5 - estilo oligárquico, com 5 itens $(\alpha=0,736),(29,27,52,30,59)$. Dimensão 6 - estilo local, com 3 itens $(\alpha=0,689),(24,01,44)$. Diante dessa organização, foram excluídos os itens que não apresentaram índice de carga fatorial suficiente (itens 19, 37, 49, 65) ou carregaram em dimensão nãocongruente teoricamente (itens $2,3,4,6,7,9,10,12,14,15,16,18,20,21,22,23,25,33,35,37,38$, $40,42,45,47,48,50,51,53,56,57,58,61,62,64)$.

A versão utilizada no presente estudo foi traduzida e também foi efetivada a retrotradução, não tendo passado por estudo de adaptação ou validação para o contexto brasileiro. Para o procedimento de tradução do TSI-R2 contou-se com a participação de dois juízes independentes, ambos bilingues português-inglês que efetivaram a tradução. $O$ procedimento de retrotradução foi realizado por um juíz nativo na língua inglesa (norteamericana), que efetivou a tradução do instrumento novamente para o inglês.

Pretendeu-se fazer um estudo com essa população partindo da versão norteamericana, considerando que esse instrumento foi idealizado para indivíduos de nível instrucional semelhante, ou seja, ensino médio e ensino superior. Dessa forma, encontrou-se sentido em verificar como estaria o funcionamento dessa escala para a realidade brasileira. Nessa versão, semelhante à norteamericana, o inventário se estabeleceu em 6 dimensões, sendo que as dimensões executivo e conservador se tornaram uma só $(\alpha=0,815)$, bem como as dimensões legislativo e interno $(\alpha=0,705)$. Sendo assim, foram perdidas as dimensões de estilo judicial, hierárquico, anárquico, global e liberal.

Cabe esclarecer que, após a realização deste estudo, observou-se a necessidade de adaptação dos itens para a realidade brasileira, sendo que o instrumento foi encaminhado a juízes para readequação dos itens. Há que se informar ainda que os estudos inerentes à busca de evidências de validade para o instrumento se encontram em andamento no contexto brasileiro. 


\section{Procedimentos}

A presente pesquisa se respaldou na Resolução 466/12 e seus complementos do Conselho Nacional de Saúde, assim o projeto foi encaminhado ao Comitê de Ética em Pesquisa com Seres Humanos - CEP de uma universidade pública estadual paranaense, que aprovou e efetivou as devidas autorizações. Após aprovação do CEP, a coleta de dados foi iniciada, de forma coletiva, tendo duração aproximada de 30 a 40 minutos em cada turma de alunos. Participaram os alunos que, juntamente com seus pais/responsáveis, consentiram a participação expressa por meio do termo de consentimento livre e esclarecido. Cabe esclarecer que os mesmos procedimentos foram adotados nas duas escolas públicas do Estado de Minas Gerais, tendo sido realizada a coleta de dados de forma coletiva, após autorização das instituições participantes e dos pais/responsáveis pelos estudantes.

\section{Análise de Dados}

Os dados foram organizados em planilha e submetidos à estatística descritiva e inferencial realizada por meio do Programa IBM SPSS (Statistical Package for the Social Sciences) versão 22.0, visando ao atendimento dos objetivos estabelecidos. Para o teste de diferença de médias foi empregado o teste $t$ de Student para amostras independentes.

\section{Resultados}

Os dados foram analisados considerando-se o perfil dos estilos intelectuais dos alunos constituídos com base na Teoria do Autogoverno Mental, que classifica os estilos intelectuais em 13 dimensões (legislativo, executivo, judicial, hierárquico, oligárquico, monárquico, anárquico, global, local, interno, externo, liberal e conservador) (ZHANG; STERNBERG, 2005). Cabe lembrar que em cada dimensão proposta a pontuação pode variar de 0 a 35 pontos, haja vista que cada uma apresenta 5 itens. Dessa forma, a Tabela 2 apresenta os resultados dos participantes relativos à Média de pontos, Desvio Padrão $(D P)$, pontuações máximas e mínimas. 
Tabela 2 - Média de pontos, Desvio Padrão (DP), pontuações mínimas e máximas da amostra geral

\begin{tabular}{lccc}
\hline \multicolumn{1}{c}{ Estilo } & $\boldsymbol{M}$ & $\boldsymbol{D P}$ & $\begin{array}{c}\text { Pontuações Mínimas e } \\
\text { Máximas }\end{array}$ \\
\hline Legislativo & 23,5 & 6,2 & $8-35$ \\
Executivo & 21,5 & 5,3 & $7-35$ \\
Judicial & 22,8 & 5,9 & $5-35$ \\
Global & 19,4 & 4,9 & $5-35$ \\
Local & 20,6 & 5,7 & $5-35$ \\
Liberal & 22,6 & 6,2 & $7-35$ \\
Conservador & 19,4 & 5,9 & $5-35$ \\
Hierárquico & 23,3 & 5,8 & $7-35$ \\
Monárquico & 22,5 & 5,8 & $6-35$ \\
Oligárquico & 19,2 & 5,9 & $5-35$ \\
Anárquico & 21,1 & 5,4 & $7-35$ \\
Interno & 20,7 & 6,0 & $5-35$ \\
Externo & 23,1 & 6,4 & $5-35$ \\
\hline
\end{tabular}

Fonte: Elaborado pelas autoras

Empregou-se o teste Qui-quadrado para verificar se a distribuição entre as médias da amostra não era equitativa. Os resultados indicaram que não houve diferença estatisticamente significante entre elas ao nível de 0,05. Observou-se que os perfis com maior média de pontuação foram legislativo, hierárquico e externo. Do mesmo modo o perfil menos pontuado foi o oligárquico.

Referente à comparação entre o 1 을 3 o anos, foi observado que apenas três perfis apresentaram diferença estatisticamente significante em razão dos anos dos alunos, quais sejam, estilo local $t=-2,344$ e $p=0,019$; hierárquico $t=-2,558$ e $p=0,011$ e anárquico $t=0,2198$ e $p=0,028$. Na Tabela 3 é possível observar as Médias de pontos dos alunos e Desvio Padrão (DP) em razão do ano escolar, considerando cada dimensão do Inventário de Estilos de Pensamento/Intelectuais (TSI-R2) (STERNBERG; WAGNER; ZHANG, 2007). 
Tabela 3 - Média de pontos e Desvio Padrão (DP) considerando o ano escolar

\begin{tabular}{lccl}
\hline Estilo & Ano & $M$ & $D P$ \\
\hline Legistativo & 1 & 23,3 & 6,2 \\
Executivo & 3 & 23,6 & 6,1 \\
Judicial & 1 & 21,3 & 5,6 \\
& 3 & 21,6 & 5,0 \\
Global & 1 & 22,4 & 6,2 \\
& 3 & 23,2 & 5,6 \\
Local & 1 & 19,1 & 5,0 \\
& 3 & 19,6 & 4,9 \\
Liberal & 1 & 20,0 & 5,7 \\
& 3 & 21,1 & 5,6 \\
Conservador & 1 & 22,3 & 6,3 \\
\multirow{3}{*}{ Hierárquico } & 3 & 23,0 & 6,1 \\
& 1 & 19,3 & 6,3 \\
Monárquico & 3 & 19,4 & 5,6 \\
& 1 & 22,6 & 6,1 \\
Oligárguico & 3 & 23,9 & 5,4 \\
\multirow{2}{*}{ Anárquico } & 1 & 22,2 & 5,9 \\
Interno & 1 & 22,8 & 5,6 \\
& 3 & 18,7 & 6,2 \\
Externo & 1 & 19,6 & 5,6 \\
& 3 & 20,5 & 5,5 \\
& 1 & 21,5 & 5,2 \\
& 3 & 20,4 & 5,8 \\
& 1 & 21,0 & 6,1 \\
& 3 & 22,7 & 6,8 \\
& 23,4 & 6,0 \\
\hline
\end{tabular}

Fonte: Elaborado pelas autoras

Observou-se mediante a Tabela 3 que a menor pontuação foi no estilo oligárquico no grupo dos alunos dos 10 anos. A maior pontuação foi encontrada no estilo hierárquico no grupo dos alunos dos 3ㅇ anos.

\section{Discussão}

Foi possível constatar que os perfis com maior média de pontuação foram legislativo, hierárquico e externo. Os perfis legislativo e hierárquico pertencem ao Tipo I dos estilos intelectuais, que é caracterizado por exigir níveis mais altos de complexidade cognitiva e denota valores mais adaptativos, por se relacionar com traços da personalidade mais favoráveis (ZHANG, 2015). Tal fato se mostra consoante com a literatura internacional, haja vista que os estudos de Tai (2012) e Zhang e Fu (2017) também evidenciaram uma preferência por parte dos alunos do ensino médio na utilização dos 
estilos do Tipo I no momento da aprendizagem, sendo que, em relação ao segundo estudo, evidenciouse que os alunos com preferência na utilização de estilos do Tipo I estão propensos a desenvolver melhores estratégias para solucionar seus problemas. Ao se considerar que os estilos do Tipo I são preferíveis em oposição aos demais Tipos, sendo ainda os mais adequados ao contexto educacional, pode-se dizer que os estudantes do ensino médio da amostra pesquisada demonstram possuir características adequadas e importantes ao desenvolvimento das habilidades acadêmicas.

Pode-se ponderar ainda, diante dos resultados, que os estudantes preferem trabalhar em grupos (estilo externo), executar várias tarefas ao mesmo tempo segundo seu grau de importância (estilo hierárquico) e ainda preferem escolher as tarefas a serem realizadas, com traços de criatividade (estilo legislativo). Esses resultados parecem estar de acordo com características próprias do desenvolvimento dos jovens nessa faixa etária, em que o pertencimento a grupos e a liberdade nas escolhas se faz presença constante. Além disso, os estilos legislativo e hierárquico estão relacionados com o uso de estratégias de enfrentamento, ou seja, os estudantes que utilizam tais estilos preferem formas diretas para lidar com seus problemas (HASSAN, 2014).

Em relação ao estilo menos pontuado no ensino médio, o estilo oligárquico, pode-se pressupor que apesar de os estudantes demonstrarem uma preferência por escolher as próprias tarefas (estilo legislativo), os mesmos não tendem a executar essas tarefas ao mesmo tempo sem estabelecer prioridades, resultado este que está de acordo com a pontuação mais alta no estilo hierárquico, que evidencia a preferência pela realização de tarefas segundo sua importância. Esse resultado também parece consoante com a fase do desenvolvimento, característica da adolescência, em que é possível observar frequentemente a realização de diversas atividades ao mesmo tempo, sendo as tarefas realizadas hierarquicamente segundo sua importância. No entanto, esses dados devem ser observados com cautela, haja vista que não foram encontrados da literatura outros estudos que apresentem tal resultado, necessitando de outros trabalhos para se obter esclarecimentos acerca da hipótese sugerida.

Em relação aos resultados da análise das diferenças do perfil de estilos considerando os alunos dos 1 으 e 3을 anos, observou-se que apenas três perfis apresentaram diferença estatisticamente significante em razão dos anos dos alunos, quais sejam, os estilos local $(M=21,1)$, hierárquico $(M=23,9)$ e anárquico $(M=21,5)$. Em todos esses perfis os alunos dos 3 anos obtiveram uma pontuação maior. Assim, observou-se que os alunos do último ano tendem a ter ideias concretas e se detêm em muitos detalhes (estilo local). Também parecem se orientar à priorização de tarefas segundo sua importância 
(estilo hierárquico) e parecem ter preferência por tarefas flexíveis (estilo anárquico). Esse achado é interessante e pode ser possível hipotetizar que os alunos do 30 ano, embora tenham demonstrado perfil local e hierárquico, apresentam característica do perfil de estilo anárquico talvez (por isto hipótese) o fato de estarem no final da adolescência e início da vida adulta pode explicar o perfil anárquico nos alunos mais velhos (3 ano). Esses alunos num futuro muito próximo ingressarão no mercado de trabalho e/ou no ensino superior, de modo que já apresentam um traço mais livre/anárquico em termos do próprio estilo. Autores como Polydoro e Casanova (2015) apontam que a etapa do ensino médio tem uma característica particular que são as questões de identidade e instabilidade dos estudantes, talvez e de forma hipotética isto explicaria o perfil de estilo anárquico.

Posto que a menor pontuação dos alunos do 1ำ ano foi no estilo oligárquico e do 3ำ ano no estilo conservador, pode-se ponderar que os estudantes, ao iniciarem a segunda etapa do ensino básico brasileiro, ainda encontram resquícios dos modelos de aprendizagem do ensino fundamental, isso porque Oliveira, Inácio e Buriolla (2016), ao analisar o perfil dos alunos de todas as etapas do ensino fundamental, identificaram que os estilos oligárquico e conservador estão presentes predominantemente em alunos de 2 음 ao 4 ㅇ anos, tendo os alunos de 8 ㅇ e 9 으 anos as menores médias nesses estilos. $O$ estilo oligárquico se refere à preferência por realizar várias tarefas ao mesmo tempo sem o estabelecimento de prioridades e o estilo conservador diz respeito à preferência pelo cumprimento de regras e procedimentos fixos.

Conforme observam Fan (2016) e Zhang (2015), pode-se considerar que a maior pontuação dos alunos do 3으 ano no estilo hierárquico pode ser resultado de uma mudança característica do avanço das etapas escolares. Os resultados, discutidos anteriormente, mostraram que no 1 o ano os alunos não gostam de realizar várias tarefas ao mesmo tempo sem o estabelecimento de prioridades (estilo oligárquico), enquanto no 3 o ano, há uma preferência na realização de várias tarefas ao mesmo tempo em uma hierarquia de prioridades (estilo hierárquico). A esse respeito Oliveira, Inácio e Buriolla, (2016) e Zhang (2015), assinalam que os estudantes podem alterar seus estilos intelectuais a depender do meio onde estão inseridos ou ainda das características e estilos utilizados por seus professores. Isso aponta para a relevância da realização de outras pesquisas que possam confirmar quais variáveis influenciam a mudança dos estilos intelectuais em alunos do ensino médio do 1 응 a 3 음 ano.

Posto ao que foi apresentado, há que se mencionar que o presente estudo teve caráter exploratório, sendo necessária a utilização de delineamentos mais sofisticados em pesquisas futuras, além de se recomendar o uso da escala com a versão adaptada e validada para o contexto brasileiro. 
Outro aspecto é a limitação da amostra, que deve ser ampliada e mais diversificada, de modo a agregar outros Estados. Por fim, evidencia-se a relevância deste estudo enquanto introdutório nas pesquisas sobre a temática dos estilos intelectuais no Brasil buscando trazer contribuições que favoreçam a compreensão de suas características e auxilie no contexto escolar, para que os alunos possam identificar seus estilos e fazer uso dos mesmos em sala de aula, podendo contribuir para um melhor desempenho nesse contexto. Aliado a isso, entende-se que, no ensino médio mais especificamente, a compreensão dos estilos intelectuais pode contribuir para o autoconhecimento desses jovens, que ao identificarem o modo preferido de utilizar suas habilidades, possam desenvolvê-las com maior profundidade, visando à utilização das mesmas em diversos contextos que extrapolam o ambiente escolar e acadêmico.

\section{Referências}

ABRAMOVAY, M.; CASTRO, M. G. Ensino Médio: múltiplas vozes. Brasília: UNESCO, 2003.

ALMEIDA, L. S. Facilitar a aprendizagem: ajudar aos alunos a aprender e a pensar. Psicologia Escolar e Educacional, v. 6, n. 2, p. 155-165, dez. 2002. Disponível em: $<$ http://pepsic.bvsalud.org/scielo.php?script=sci arttext\&pid=S1413-

85572002000200006\&lng=pt\&nrm=iso>. Acesso em: 24 jul. 2017.

BORUCHOVITCH, E. Aprender a aprender: propostas de intervenção em estratégias de aprendizagem. Educação Temática Digital, v. 8, n. 2, p. 156-167, jun. 2007.

EMIR, S. Contributions of teachers' thinking style to critical thinking dispositions (Istanbul-Fatih sample). Educational Science: Theory \& Practice, v. 13, n. 1, p. 337-347, 2013. Disponível em: <http://files.eric.ed.gov/fulltext/EJ1016649.pdf>. Acesso em: 16 jul. 2017.

FAN, J. The role of thinking styles in career decision-making self-efficacy among university students. Thinking Skills and Creativity, v. 20, p. 63-73, 2016.

FAN, J.; ZHANG, L. F. The role of perceived parenting styles in thinking styles. Learning and Individual Differences, v. 32, p .204-211, 2014.

FRIGOTTO, G.; FRANCO, M. C.; RAMOS, M. (Orgs.). o ensino médio integrado. Concepção e contradições. São Paulo: Cortez, 2005.

GOMES, C. M. A.; MARQUES, E. L. L.; GOLINO, H. F. Validade incremental dos estilos legislativo, executivo e judiciário em relação ao rendimento escolar. Revista Eletrônica de Psicologia, Educação e Saúde, v. 3, n. 2, p. 31-46, fev. 2014. Disponível em: <http://revistaepsi.com/wpcontent/uploads/artigos/2013/Ano3-Volume2-Artigo3.pdf>. Acesso em: 16 jul. 2017.

HASSAN F. S. Relationship between coping strategies and thinking styles among university students. ASEAN Journal of Psychiatry, v. 15, n. 1, p. 14-22, 2014 . Disponível em: $<$ https://www.aseanjournalofpsychiatry.org/index.php/aseanjournalofpsychiatry/article/view/173/1 38>. Acesso em: 16 jul. 2017. 
HANNON, B.; DANEMAN, M. A new tool for measuring and understanding individual differences in the component processes of reading comprehension. Journal of Educational Psychology, v. 93, n. 1, p. 103-128, 2001.

KRAWCZYK, N. Ensino Médio: empresários dão as cartas na escola pública. Educ. Soc., v .35, n. 126, p. 21-41, jan./mar. 2014.

OLIVEIRA, K. L.; INÁCIO, A. L. M.; BURIOLLA, H. L. Diferenças considerando ano escolar no ensino fundamental: um estudo com estilos intelectuais. Argumentos Pró-Educação, v. 1, n. 3, p. 408-422, 2016.

OLIVEIRA, K. L.; SANTOS, A. A. A.; SCACCHETTI, F. A. P. Medida de estilos de aprendizagem para o ensino fundamental. Psicologia Escolar e Educacional, v. 20, n. 1, p. 127-136, 2016.

POLYDORO, S.; CASANOVA, D. C. G. Escala de Autoeficácia Acadêmica para o Ensino Médio: busca de evidências psicométricas. Estudos Interdisciplinares em Psicologia, v. 6, n. 1, p. 36-53, 2015.

STERNBERG, R. J. Psicologia Cognitiva. 5. ed. Porto Alegre: Artmed, 2010.

STERNBERG, R. J.; WAGNER, R. K. Thinking Styles Inventory. Unpublished manual, Yale University, 1992.

STERNBERG, R. J.; WAGNER, R. K.; ZHANG, L. F. Thinking styles inventory: revised. Unpublished: Yale University, 2003.

STERNBERG, R. J.; WAGNER, R. K.; ZHANG, L. F. Thinking styles inventory - Revised II (TSI-R2), Tufts University, 2007.

TAI, R. The impact of teaching styles on students' learning styles and career interests. PhD Thesis, University of Hong Kong, Hong Kong, 2012. Disponível em: <http://www.airitilibrary.com/Publication/alDetailedMesh?docid=U0029-0511201300009102>.

Acesso em: 08 jun.2017.

WOOLFOLK, A. Psicologia da Educação. Porto Alegre: Artmed, 2000.

ZHANG, L. F. The developing field of intellectual styles: Four recent endeavours. Learning and Individual Differences, v. 21, n. 3, p. 311-318, 2011.

. Fostering successful intellectual styles for creativity. Asia Pacific Educational Review, v. 16, n. 2, p. 183-192, 2015.

ZHANG, L. F.; FU, M. Thinking styles and academic stress coping among Chinese secondary school students. Educational Psychology, v. 37, p. 1015-1025, 2017.

ZHANG, L. F.; STERNBERG, R. J. A threefold model of intellectual styles. Educational Psychology Review, v. 17, n. 1, p. 1-53, 2005.

ZHANG, L.; STERNBERG, R. J.; FAN, J. Revisiting the concept of "style match". British Journal of Educational Psychology, v. 83, p. 225-237, 2013. 